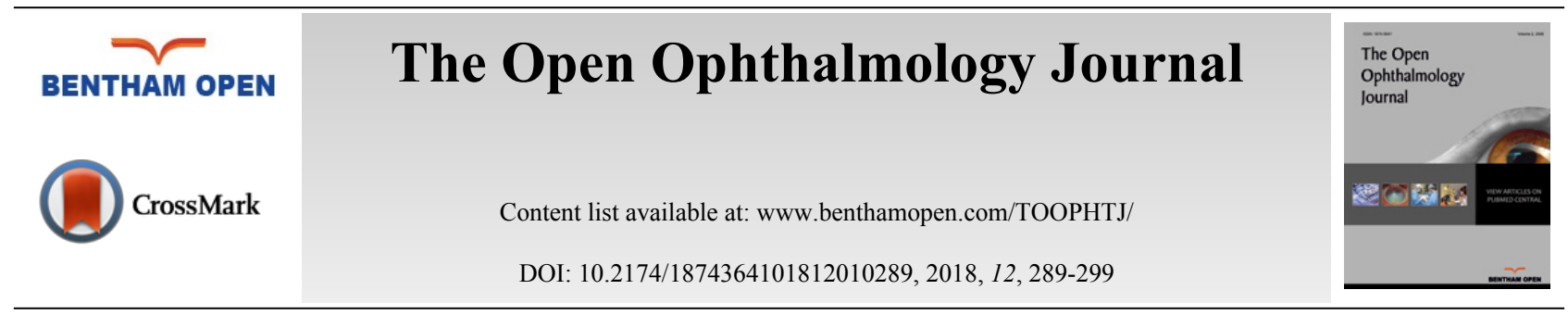

REVIEW ARTICLE

\title{
Epidemiology of Keratoconus Worldwide
}

\author{
Khor Omer ${ }^{*}$ \\ Dr.Shaheed Aso Teaching Eye Hospital, Sulaymania, Iraq
}

Received: September 12, 2018

Revised: October 03, 2018

Accepted: October 5, 2018

\begin{abstract}
:
In our paper, we will discuss the epidemiological differences that are present around the world as it is expected that the difference may be due to the genetic environment or habitual and nutritional causes.

The word Keratoconus (KC) comes from the Greek words: Kerato (Cornea), and Conos (cone).

Keratoconus is a bilateral noninfectious, non-inflammatory disorder of the eye which results in gradual thinning of the cornea and distorted vision. It occurs in late childhood to early adulthood.

This degenerative condition of the cornea results in thinning of the stromal layer with consequent forward bulging of the normal shape cornea into a conical shape due to the structural weakness of the collagen fibers.

The induced abnormal profile leads to high levels of astigmatism, often combined with myopia (Nearsightedness).

Due to the progressive distortion of the cornea's front surface, it may become increasingly difficult to correct the vision with spectacles or contact lenses, and in some patients, it may lead to hydrops formation and corneal opacity.

As we know that the cause is unknown until present day but there is a large epidemiological difference between different areas of the world and different ethnicities, and there is an increase in the number of cases occurring nowadays in the world which may be due to technology advancement or better methods of diagnosis.
\end{abstract}

Keywords: Epidemiology, Keratoconus, Prevalence, Risk factors, Cornea, Conos.

\section{INTRODUCTION}

Keratoconus is a clinical term used to describe the condition in which the cornea assumes a conical shape because of thinning and protrusion of the corneal stroma, the word comes from the Greek words: Kerato (Cornea), and Conos (cone).

Keratoconus is a bilateral noninfectious, non-inflammatory disorder in which cellular infiltrates and neovascularization do not occur. The corneal thinning is the hallmark of this ectatic disorder which results in gradual thinning of the cornea and distorted vision. It usually begins in late childhood to early adulthood and progress usually till 35-40 years old. The reduction of vision can vary from mild to severe according to the changes that occur.

This noninflammatory thinning of the corneal stroma will result in the conical shape of the cornea and it involves usually central $2 / 3$ of the cornea from which the temporal inferior para central zone are involved most commonly leading to, a corneal protrusion which in turn lead to myopic shift and high irregular astigmatism. This irregular astigmatism leads to mild to severe distortion and impairment of vision depending on the degree and location of the protrusion.

Due to the progressive nature of the disorder, it may become gradually difficult to correct the vision with spectacles * Address correspondence to this author at the Dr.Shaheed Aso Teaching Eye Hospital Sulaymania, Iraq; Tel: 009647701529100; E-mail:
Khorsirwan@yahoo.com 
or contact lenses. In some patients, it may lead to hydrops formation and corneal opacity, which may require surgical intervention.

As we know that the cause is unknown until the present day but there is a large epidemiological difference between different areas of the world and different ethnicities, and there is an increase in the number of cases occurring nowadays in the world which may be due to technology advancement or better methods of diagnosis like Corneal tomography and topography which have dramatically improve the sensitivity of the diagnosis and detection of these ectatic disorders.

In our paper, we will discuss the epidemiological differences that are present around the world as it is expected that the difference may be due to the genetic environment or habitual and nutritional causes

\section{DISCUSSION}

\subsection{Incidence}

The incidence of keratoconus differs according to different publications and paper and also it differs according to the geographical location around the world.

In the Wikipedia, as a general source of information, it is mentioned that the incidence is 1 in 2000 people and $7 \%$ have a family history of the disease.

According to other authors, the frequency is lower, between 0.0003 in Russia than and as high as $2.3 \%$ as in the population studied by Jonas in the Maharashtra region in central India [1].

Higher incidence in other geographical areas was detected in New Zealand and Asir province in Saudi Arabia [1], and in another study, the prevalence in population based in Israeli Arabs was recorded to be 3.18\% (124). This high incidence in different studies could be partly explained by the high UV exposure of their population [1].

In other areas of the world, the incidence differs as shown by Kennedy in his study in Minnesota USA in 1986 in which the incidence is 6/1000 [2] and according to Applebaum 4/1000(applebaum1936) [1].

Estimated annual incidence of keratoconus ranges from 50 to 230 cases per 100,000 population [3], elsewhere the incidence has been estimated at 1.3/100000/year in the Danish population in Denmark [4], Ethnic differences are influential, as a study in UK by Pearson et al demonstrated annual incidence of keratoconus of 19.6/100000 in Asian and 4.5/100000 in Caucasian communities [5].

This difference in keratoconus between different populations is probably multifactorial in terms of genetic, nutrition and environmental factors.

The Middle East countries in particular, as well as parts of India, are characterized by hot and sunny climates with very little rain which is distinctive from the other countries. Therefore, the climate may influence the development of keratoconus, especially the oxidative damage caused by excessive sun exposure to ultraviolet light [6] rays that may cause enzymatic change or modulation of the enzymes which gradually lead to change in collagen or there may be a difference in genetic or inheritance factor in these societies, or there could be a variety in different styles of life with nutrition that plays a role? There is also the possibility that in these countries the disease affects more the poor people, a factor known to increase the proportion of chronic diseases [7] (Table 1).

Table 1. Table of Incidence.

\begin{tabular}{|c|c|c|c|c|c|}
\hline Author & Location & Age & Sample Size & $\begin{array}{c}\text { Prevalence In } \\
\mathbf{1 0 0 0 0 0}\end{array}$ & Source \\
\hline Hof Stetter & Indianapolis,USA & $001-79$ & 13395 & 500 & Population \\
\hline Tanabe & Muroran, Japan & $010-60$ & 2601 & 9 & Hospital \\
\hline Jonas & $\begin{array}{c}\text { Maharashtra, } \\
\text { India }\end{array}$ & $>29$ & 4667 & 2300 & Population \\
\hline Millodot & Jerusalem, Israel & $18-54$ & 981 & 2340 & Population \\
\hline Ljubic & Skope, Macedonia & - & 2254 & 6.8 & Population \\
\hline Ziaei et al. & Yazd, Iran & $16-35$ & 536 & 22.33 & Students \\
\hline Hashemi H & Mashed, Iran & $22-29$ & 1079 & $2.4 \%$ & Army recruits \\
\hline Santigo & France & $18-22$ & 670 & 1190 & \\
\hline
\end{tabular}


(Table 1) contd....

\begin{tabular}{|c|c|c|c|c|c|}
\hline Aable 1) contd..... & Location & Age & Sample Size & $\begin{array}{c}\text { Prevalence In } \\
\mathbf{1 0 0 0 0 0}\end{array}$ & Source \\
\hline Xu et al. & Beijing, China & $50-93$ & 3166 & 27 & Rural \\
\hline Hashemi et al. & Tehran & $20-34$ & 1073 & 26 & Urban volunteer \\
\hline Godefrooij DA & Netherlands & $10-40$ & 4 million & 13.3 & Mandatory health insurance data base \\
\hline Mohammed Othman & Egypt & $21-36$ & 2116 & 170 & Population \\
\hline
\end{tabular}

\section{RISK FACTORS}

As we know that keratoconus is thought to be a multiple factorial disorder. Multiple factors implicated in the pathogenesis of keratoconus include genetic and environmental factors among which the following are the most common.

\subsection{Genetic}

The high incidence and increasing prevalence of keratoconus are thought to be caused by the better quality and more advance in diagnostic tools and higher prevalence of people asking for refractive surgery nowadays, that may be the cause of more cases than have been diagnosed in the past.

Keratoconus is thought to be caused by a complex interplay of environmental and genetic factors. It is a biomechanical and biochemical disorder [8].

Varying prevalence among groups of different ethnicity living in same geographical location suggests a genetic basis for the disease, for example, a higher prevalence than the British average has been found in Indian and Pakistani communities living in UK [9].

Further evidence for genetic basis includes a significant association with consanguinity [10]. 10\% of patients with keratoconus had a family history of the disease compared with just $0.05 \%$ of the age-matched control group [11].

Epigenetic modification of normal cornea may result from environmental stressors including toxins and microbial exposure [12]. They may cause a trigger for the keratoconus development in those patients.

Although the most common type of keratoconus is sporadic, other may show that the keratoconus has hereditary bases in some cases. The US Collaborative Longitudinal Evaluation of Keratoconus study reported a rate of family history of $13.5 \%$, and a study from Israel-where the prevalence of $\mathrm{KC}$ is high-reported a rate of family history of $21.74 \%$, which was higher than $13 \%$ which we reported previously [12].

Many studies were conducted to find the incidence of familial keratoconus worldwide but they showed different incidence values. The rate ranges from $5 \%$ to $27.9 \%$ [13 - 17]. In one of the studies in which a rate of $27.9 \%$ of keratoconus was found in at least one person in the family, it was further noted that affected first-degree relatives represented $20.5 \%$ [13].

Current thinking is that, geographic variation in the prevalence can be explained by specific environmental factors promoting the expression of the genetic factors related to ethnicity [18].

It seems that an environmental factor may be essential to act as a trigger of the condition in genetically predisposed individuals. Environmental factors, which have been recognized are eye rubbing, atopy, and UV exposure, although the relative contribution of all these factors is currently unknown [19].

But the most common interactions between environmental and genetic factors that have been discussed in different studies are ultraviolet light exposure and eye rubbing [18].

\subsection{Ethnic Groups}

Keratoconus is a worldwide disorder and the prevalence is different among different ethnic groups in the same geographical part of the world. This has been supported by numerous epidemiological studies that show ethnicity and environmental factors are likely to play a major cause in the etiology of the disease.

Until some years ago it was assumed that keratoconus affected all races equally [20]. However, different studies have illustrated that there is a difference in incidence according to ethnicity.

For example, in Lebanon a high prevalence of 3.3\%, in Indian rural areas $2.3 \%$, while there is a lower prevalence in 
cold north of Denmark, Finland and Russia [8].

Zadnik found prevalence rate of $68.5 \%$ in CLEK population, $19.9 \%$ in Caucasians black and $8.2 \%$ in Hispanics [21], while Owen found no ethnicity influence in New Zealand [22]. In Singapore, high K reading of cornea possibly reflecting keratoconus was found to be significantly higher in Indians than in Malays or Chinese [23].

In another study, the prevalence of Keratoconus among Young Arab Students in Israel Data of 314 participants was analyzed and found to be $3.18 \%$ (95\% CI, 1.2 to $5.1 \%$ ) [24]. The only significant factor (both in univariate and multivariate analysis) that was found to be associated with keratoconus was parental consanguinity $(\mathrm{OR} 5.10, \mathrm{p}=0.02)$. In another study, Druze's and Bedouins had a higher prevalence than Muslims and Christians. However, the differences were not statistically significant possibly due to the small size of the sample used in the study [24].

\subsection{Ultraviolet and Sun Exposure}

Ultraviolet is regarded as one of the main causes for the development of keratoconus because of its oxidative damage, this can be illustrated by its high prevalence in hot and sunny areas.

It is proposed that UV light will lead to excessive production of reactive oxygen species within the cornea and that in cases of keratoconus they lack the ability to process this excess reactive oxygen species which eventually lead to oxidative stress, cytotoxicity and corneal thinning [8].

Higher prevalence of keratoconus has been identified in Saudi Arabia Iran, New Zealand, Israel and some Pacific Islands [8]. One of the explanations is high ultraviolet exposure.

Studies demonstrated that UV exposure is important for the development of keratoconus, but other environmental factors may play a role in determining the prevalence of keratoconus. In a study, Asians living in UK have a prevalence of KC 7.6 times that of Caucasians suggests that nonenvironmental (i.e. Genetic) factors are predominant .Similarly, in other studies, the prevalence of keratoconus is much higher in non-Persians (Arab, Turks and Kurds) living in Tehran (7.6\%) than Persians (2.5\%) [8].

However, it must be noted that UV radiations might also provide a beneficial effect by inducing auto cross-linking of corneal collagen, thus mitigating either the development or the progression of the disease [25].

\subsection{Eye Rubbing}

Eye rubbing is also regarded as another major environmental stressor in the development of keratoconus .It is thought to cause corneal injury by the following mechanism: Recurrent epithelial trauma results in the release of matrix metalloproteinase 1 and 13, interleukin-1 and tumor necrosis factor alpha that lead to stromal remodeling and keratocyte apoptosis [8], This, in turn, may cause epigenic modification and will affect genetically susceptible individuals by affecting the gene expression for the development of keratoconus in those individuals .

Another mechanism for causing keratoconus in atopy patients is increased IOP that may be associated with the progression of keratoconus, especially in young patients [26].

Interestingly the duration of eye rubbing in patients with keratoconus appears longer than that associated with atopy [27] possibly explaining why the high percentage of atopic patients do not develop keratectasia due to rubbing.

It is important that how the patient rubs the eye either gently or vigorously [28] and also the duration of the eye rubbing, for example, the usual length of rubbing in $\mathrm{KC}$ patients is much longer (from 10 to 180 seconds) while it is typically less than 15-second duration of rubbing in allergic or infective disorder [28] and in healthy people without any eye pathology it is less than 5 seconds.

Tretter showed that keratoconus patients do rub their eyes more often than normal subjects ( $80 \%$ vs $58 \%$ ) [2], while the CLEK study showed that $48 \%$ of keratoconus patients rubbed both eyes vigorously while $2.2 \%$ rubbed one eye.

Direct experimental evidence of an association between keratoconus and eye rubbing has been demonstrated in a study. A group of volunteers without the disease and not wearing contact lenses who were instructed to rub their eyes in a controlled fashion for 60 seconds. Later the basal tears were collected before and after eye rubbing and it was found that levels of MMP-13, IL- 6 and, TNF- $\alpha$ were significantly increased after rubbing. It was concluded that persistent eye rubbing, which is very common in keratoconus patients, may contribute to the progression of the disease by continuously elevated levels of these proteases, inflammatory mediators and protease activity [29, 30]. 


\subsection{Gender}

There is no clear evidence that keratoconus is affected by the sex of the patient.

Multiple studies were performed on gender difference in keratoconus. They vary between studies, some demonstrated female predominance and other showed male predominance and some studies showed no significant gender predominance [8]

Certain studies show female predominance such as Amsler in 1961 (65\%). Laqua 1971 (57\%) Hammerstein in 1972 $(66 \%)$ and Jonas in 2009 (53\%) [1].

In contrary to this, other studies found a male predominance. This is the case for Pouliquen in 1981 [57\%], Street in 1991 (62\%) Pobelle-frasson in 2002 (62\%) Owen in 2003 (59\%) and Fatima (53\%) and Ertan (62\%) in 2009 [1], while other studies did not find any difference between male and female [1].

In another study, Fink found that there is a difference in the frequency of familial keratoconus hereditary $(17 \%$ female to $11 \%$ male) [31].

\subsection{Hormonal}

Hormones have also been indicated as a possible cause of keratoconus because of association of puberty with the disease onset and there have been many case reports of stable keratoconus, which all of a sudden progress during pregnancy when there is another surge of hormonal change.

Although it is recognized that sex and hormones affect the corneal structure but there is no solid evidence that hormones affect keratoconus progression .Reports of patient populations with keratoconus contain limited information about how sex hormone modulate the expression of disease [1]. Fink also tried to show a hormonal effect but did not find any significant difference [31].

\subsection{Age}

The age is one of the important factors that we depend on, in the diagnosis and management of this disorder because the progression of the diseases differs according to the age of the patient and the treatment strategy will change also according to their age.

Keratoconus is regarded as a disease of adolescent between the ages of 20-30, the clinical onset is at puberty and develops until $3^{\text {rd }}$ to $4^{\text {th }}$ decay (31) the average age is as follows as reported in different literatures:

Pouliquen 1981: 20.4 [32]

Kennedy 1986: 29 years [2]

Tuft1992: 25 years [33]

Zadnik1998: 28 years [21]

Owen 2003: 22.9 years [22]

Saini reported that eye with severe keratoconus present at younger average age $(18.8+/-5.35$ years $)$ than moderate keratoconus (23.69+/- 8.07 years) [34].

With age, the progression decrease may be as we know that collagen interfibrillar spacing decreases with age where collagen bundles become thicker. These structural changes may modify the rigidity and elasticity of the cornea. An increase corneal rigidity with age could be a hypothesis explaining the decrease of keratoconus with increasing age [1].

In a cohort of 196 patients, in this study, it was demonstrated that, 18 years old was the most frequent age of onset and in another study by Romagnani it was $15.39( \pm 3.95)$. However, most reports give the age of diagnosis, which is some years after onset because the disease is usually asymptomatic at first. The mean diagnostic age ranged from 20.0 years $( \pm 6.4)$ to $24.05( \pm 8.97)$ in most studies [35].

Because of the chronicity of the disease, one will expect to find similar results in older age groups than in younger ones. But that is not the case, especially after the age of 50 years and this has intrigued many authors [36], although in one study the number of old keratoconus patients was found to be substantial (697 patients were examined) [37]. Most of these studies report low percentage of keratoconus patients beyond 50 years, ranging from $7.4 \%$ to $15 \%$ with one exception $40 \%$ [38 - 40]. The reason may be more advance in diagnostic methods like pentacam and topographies, or it 
may be because there are now more people with an allergy in the general population [41]. Another possibility is that keratoconus patients have reduced years of living compared to the general population, as has been suggested by some authors [40, 42] because of an associated fatal condition, for example, mitral valve prolapse [43, 44], obesity [45, 46], or obstructive sleep apnea [41,47], although the mortality rate of a population of KC patients was not found to be significantly different than that of the general population [48]. Nevertheless, the question as to what happens to keratoconus patients beyond the age of 50 years remains to be elucidated, possibly by comparing the corneas of older $\mathrm{KC}$ patients with an age-matched control group. [14]

\subsection{Atopy}

Atopy is regarded as another major cause of keratoconus in most literature.

The first reported association was by Hilgartner in 1937 [2] later on Brunsting et al 1955 and later Galian and burger in 1958 [35] Spencer and Fisher in 1959 [49].

Lowell and Carroll in 1970 in an analysis study found no significant difference between the incidence of the atopic trait of keratoconus and control group [50].

In larger controlled study Rahi proved within a series of 182 keratoconus cases a higher frequency of allergic disease (35\%) compared to control group (12\%) as well as higher plasma IGE level asthma eczema and hay fever [51].

A recent study in Dundee on 200 patients suffering from keratoconus revealed that; $23 \%$ were asthmatic, $14 \%$ were eczematic cases and 30\% were suffering from allergic rhinitis [52].

\subsection{Parenteral Education}

An association between keratoconus and low parenteral education was suggested because parental education is associated with socioeconomic status [15]. Children living in poverty are brought up in environments with air, water, and waste contamination problems [16], which are predisposing factors to many health issues including keratoconus. As a consequence, these children are at risk or suffer from a host of disorders, such as asthma, cancer, hyperactivity, and obesity [17].

\subsection{Floppy eyelid syndrome}

Possible association between keratoconus and this syndrome was proposed by few studies [53] but still, there is no clear evidence for this and may require more research or data.

\section{ASSOCIATED WITH CONNECTIVE TISSUE DISORDERS AND SYSTEMIC DISEASE}

As we know that collagen fiber I is a part of the connective tissue so when there is an abnormality in the connective tissue in the body there may be an abnormality in other parts of the body.

\subsection{Ehler-Danlos Syndrome}

It is a collagen disorder of the body so it may also affect the corneal collagen and so have an effect on the development of keratoconus.

Kumming was the first author to claim the association between this disorder and keratoconus. Keratoconus in this patients remain rare [54]. [55].

McDermoitt found only one patient presenting keratoconus among 72 patients who had Ehler -Danlos syndrome

\subsection{Marfan Syndrome}

Marfan syndrome is an X linked disorder, in these patients, there is a higher incidence of keratoconus than normal population but the associated of Marfan syndrome with keratoconus still remain relatively rare and not very high percent [56].

\subsection{Lonstein Disease}

Osteogenic imperfecta is a hereditary disease more commonly known as Lobstein disease which is a bone disorder affecting bone collagen, and higher incidence of keratoconus (not evolving after puberty) was described in some 
Lobstein s disease families [57, 58].

\subsection{Mitral Valve Prolapse}

Mitral valve prolapse is a condition of the mitral valve of the heart, the exact cause is not known but it is thought that there is an abnormality in collagen fibers of the mitral valve, so this abnormal collagen fiber may be present in other collagen fibers in the human body as corneal collagen.

Mitral valve prolapse according to some literature are more frequently associated with keratoconus [59], while for other literatures like Street there is no association between keratoconus and mitral valve prolapse [60].

Sharif studied mitral valve prolapse prevalence among 50 keratoconus patients this was (53\%) was much higher than that of control group (7\%)[30]these results oppose those reported by Street in 1991 [12, 60].

Frasson in 2003 published a study in which a cardiac echography of 50 keratoconus affected patients was carried out: $22 \%$ expressed a mitral valve anomaly (prolapse $4 \%$ mitral insufficiency in $10 \%$ and mitral regurgitation $8 \%$ ) this prevalence is 4 times higher than in general population. Within these patients, the genuine prolapses identified concerned patients with a developed phase of the disease [1].

A possible hypothesis that could explain an association between keratoconus and mitral valve prolapse is the presence of some common collagen types shared between these two disorders [8] which is collagen type 1 that composes corneal stroma and also mitral valve structure.

\subsection{Association with Down Syndrome}

Trisomy 21 is regarded as one of the common congenital abnormalities in the world. As we know that multiple pathologies occur in these patient including eye pathology.

Among the 143 Down syndrome patients studied by Cullen in 1963, 5.5\% expressed keratoconus [61], while other authors Pierse, Slusher, Kenyon have shown a higher incidence of acute keratoconus cases among patients having undergone ocular traumatism more frequently. Overall the rate of postoperative complications after transplant remains higher (stich breaking, traumatism, rejection...) compared to general population [1].

On the other hand, it would seem that keratoconus frequency of Down syndrome patient will vary according to the ethnic group studied. Thus, a study involving 60 Down syndrome patients living in Malaysia discovered a higher incidence of other ocular defects, such as epicanthus, nystagmus or even strabismus. Nevertheless, no keratoconus cases were found [62]. Conversely, Shapiro found a keratoconus frequency of 15\%within a population of 53 Down syndrome patients of Caucasian origin [63].

\subsection{Diabetes}

The association with diabetes is analyzed but diabetes prevalence with keratoconus is not higher than in the general population. On the other hand, diabetes patients develop less severe form [64, 65].

Biochemical property modifications of the cornea due to abnormal glycosylation of stromal collagen fibers of the cornea of a diabetic was suggested. The protective effect of diabetes in cases of keratoconus could be explained by the induction of auto cross-linking in the corneal stroma preventing biomechanical weakening of the cornea [1].

\section{OTHER OPHTHALMOLOGICAL GENETIC DISORDERS}

\subsection{Leber Congenital Amaurosis}

It is a hereditary disease causing bad eyesight from birth. This disease seems to be more associated with keratoconus compared to other blinding disease [35]. Repeated ocular rubbing (oculo- digital sign) is definitely a favoring factor, although a genetic factor could also be the cause [1].

\subsection{Corneal Dystrophies}

Keratoconus is rarely associated with corneal dystrophies [1].

\subsubsection{Endothelial dystrophy}

Darlington reported a case in which documented bilateral but asymmetrical keratoconus was associated with 
unilateral corneal guttata in the more involved eye [66].

\subsubsection{Macular Dystrophy}

Association with macular dystrophy has been described by several authors. Javadi described two cases of macular dystrophy associated with keratoconus with histopathological evidence [67 - 69].

\subsubsection{Granular Dystrophy}

It can also be associated with keratoconus, in this case, carrying out lamellar transplant is preferential for keratoconus in case of dystrophy deterioration [1].

\subsubsection{Posterior Polymorphous Corneal Dystrophy}

This is a rare autosomal dominant bilateral dystrophy of decement membrane. Some cases of keratoconus associated with PPCD have also been reported in the literature [1].

\section{CONCLUSION}

In summary, $\mathrm{KC}$ is the most common corneal ectasia and very common corneal disorder with the onset of puberty. It affects both male and female and all ethnic groups worldwide. But its incident differs from region to region and also according to ethnicity and both environmental and genetic factors contribute to the pathogenesis of KC. There are many other factors affecting the disorder like nutritional, hormonal and lifestyle of the patient.

Because keratoconus is a bilateral disorder that affects both eyes but with different severity, and it starts at young age so it affects an important part of the population which is the young group which is usually in the developing stage and an important part of the productive group of the society, therefore this disease gains a special concern by all ophthalmologist worldwide.

In turn enormous effort and a huge amount of research was done and still ongoing worldwide to know the exact cause of the disorder.

In the last 10 years, a significant amount of development has been made in the understanding of keratoconus and its etiology and epidemiology. Newly developed genetic technologies including whole exome or genome sequencing and genome-wide association technologies have promoted and will continue to improve our knowledge on the pathogenesis of KC. This advancement will lead to earlier detection of the disorder and more prompt treatment at an earlier age which leads to less vision disability and a better outcome for the disorder and better prognosis.

The understanding of the epidemiology will help us later in the treatment of the disease so important step is to identify the cause and the most important is preventing the visual impairment in this important part of the society.

\section{CONSENT OF PUBLICATION}

Not applicable.

\section{CONFLICT OF INTERESTS}

The authors declare no conflict of interest, financial or otherwise.

\section{ACKNOWLEDGEMENTS}

Decleared none.

\section{REFERENCES}

[1] Adel barbera, text book on keratoconus new insights 2012. Jaypee-highlight p3-11.

[2] Kennedy RH, Bourne WM, Dyer JA. A 48-year clinical and epidemiologic study of keratoconus. Am J Ophthalmol 1986; 101(3): 267-73. [http://dx.doi.org/10.1016/0002-9394(86)90817-2] [PMID: 3513592]

[3] Krachmer JH, Feder RS, Belin MW. Keratoconus and related non inflammatory corneal thinning disorder. Surv ophthalmol 1984; 28(40): 293-322.

[4] Nielsen K, Hjortdal J, Aagaard Nohr E, Ehlers N. Incidence and prevalence of keratoconus in Denmark. Acta Ophthalmol Scand 2007; 85(8): 890-2. 
[5] Pearson AR, Soneji B, Sarvananthan N, Sanford-Smith JH. Does ethnic origin influence the incidence or severity of keratoconus? Eye. 2000; 4(4): $625-8$

[6] Weed KH, MacEwen CJ, McGhee CNJ. The variable expression of keratoconus within monozygotic twins: Dundee University Scottish Keratoconus Study (DUSKS). Cont Lens Anterior Eye 2006; 29(3): 123-6.

[http://dx.doi.org/10.1016/j.clae.2006.03.003] [PMID: 16677846]

[7] Cristina Kenney M, Brown DJ. The cascade hypothesis of keratoconus. Cont Lens Anterior Eye 2003; 26(3): $139-46$. [http://dx.doi.org/10.1016/S1367-0484(03)00022-5] [PMID: 16303509]

[8] Jorge L. Alio Editor text book of Keratoconus recent advances in diagnosis and treatment, springer 2017; $13-23$.

[9] Pearson AR, Soneji B, Sarvananthan N, Sandford-Smith JH. Does ethnic origin influence the incidence or severity of keratoconus? Eye (Lond) 2000; 14(Pt 4): 625-8. [http://dx.doi.org/10.1038/eye.2000.154] [PMID: 11040911]

[10] Gordon-Shaag A, Millodot M, Essa M, Garth J, Ghara M, Shneor E. Is consanguinity a risk factor for keratoconus? Optom Vis Sci 2013; 90(5): 448-54.

[http://dx.doi.org/10.1097/OPX.0b013e31828da95c] [PMID: 23584486]

[11] Rabinowitz YS the genetics of keratoconus. Ophthalmol clinic North Am 2003; 16(4): 607-20.

[12] Zadnik K, Barr JT, Edrington TB, Everett DF, Jameson M, McMahon TT, et al. Baseline findings in the Collaborative Longitudinal Evaluation of Keratoconus (CLEK) Study. Invest Ophthalmol Vis Sci 1998; 39(13): 2537-46. [PMID: 9856763]

[13] Nugent R. Chronic diseases in developing countries: Health and economic burdens. Ann N Y Acad Sci 2008; 1136: 70-9. [http://dx.doi.org/10.1196/annals.1425.027] [PMID: 18579877]

[14] Ariela G S, Millodot M, Shneor E, Yutao Liu L. The genetic and environmental factors for keratoconus. BioMed Res Inter 2015 (2015), Article ID 795738, 19 pages.

[15] Moraeus L, Lissner L, Yngve A, Poortvliet E, Al-Ansari U, Sjöberg A. Multi-level influences on childhood obesity in Sweden: Societal factors, parental determinants and child's lifestyle. Int J Obes 2012; 36(7): 969-76. [http://dx.doi.org/10.1038/ijo.2012.79] [PMID: 22614053]

[16] Powell DL, Stewart V. Children. The unwitting target of environmental injustices. Pediatr Clin North Am 2001; 48(5): $1291-305$. [http://dx.doi.org/10.1016/S0031-3955(05)70375-8] [PMID: 11579675]

[17] Cureton S. Environmental victims: Environmental injustice issues that threaten the health of children living in poverty. Rev Environ Health 2011; 26(3): 141-7.

[http://dx.doi.org/10.1515/reveh.2011.021] [PMID: 22206190]

[18] McMonnies CW. Screening for keratoconus suspects among candidates for refractive surgery. Clin Exp Optom 2014; 97(6): 492-8. [http://dx.doi.org/10.1111/cxo.12169] [PMID: 25331075]

[19] Davidson AE, Hayes S, Hardcastle AJ, Tuft SJ. The pathogenesis of keratoconus. Eye (Lond) 2014; $28(2): 189-95$. [http://dx.doi.org/10.1038/eye.2013.278] [PMID: 24357835]

[20] Rabinowitz YS. Keratoconus. Surv Ophthalmol 1998; 42(4): 297-319. [http://dx.doi.org/10.1016/S0039-6257(97)00119-7] [PMID: 9493273]

[21] Zadnik K, Barr JT. Basline finding in the Collaborative Longitudinal Evaluation of Keratoconus (CLEK) study. Invest Ophthalmol Vis Sci 1998; 39: 2537-46. [PMID: 9856763]

[22] Owens H, Gamble G. A profile of keratoconus in New Zealand. Cornea 2003; 22(2): 122-5. [http://dx.doi.org/10.1097/00003226-200303000-00008] [PMID: 12605045]

[23] Pan CW, Cheng CY, Sabanayagam C, et al. Ethnic variation in central corneal refractive power and steep cornea in Asians. Ophthalmic Epidemiol 2014; 21(2): 99-105.

[http://dx.doi.org/10.3109/09286586.2014.887735] [PMID: 24527688]

[24] Shneor, Einat \& Millodot, Michel \& Gordon-Shaag, et al. Prevalence of Keratoconus among Young Arab Students in Israel. IJKECD 3: 9-14. [http://dx.doi.org/10.5005/jp-journals-10025-1070.]

[25] Chan E, Snibson GR. Current status of corneal collagen cross-linking for keratoconus: A review. Clin Exp Optom 2013; 96(2): 155-64. [http://dx.doi.org/10.1111/cxo.12020] [PMID: 23414201]

[26] McMonnies CW, Boneham GC. Corneal responses to intraocular pressure elevations in keratoconus. Cornea 2010; 29(7): 764-70. [http://dx.doi.org/10.1097/ICO.0b013e3181ca2b75] [PMID: 20489581]

[27] Krachmer JH. Eye rubbing can cause keratoconus. Cornea 2004; 23(6): 539-40. [http://dx.doi.org/10.1097/01.ico.0000137168.24883.3e] [PMID: 15256988]

[28] Carlson AN. Expanding our understanding of eye rubbing and keratoconus. Cornea 2010; 29(2): 245. [http://dx.doi.org/10.1038/sj.eye.6702692] [PMID: 17237755] 
[29] Balasubramanian SA, Pye DC, Willcox MDP. Effects of eye rubbing on the levels of protease, protease activity and cytokines in tears: Relevance in keratoconus. Clin Exp Optom 2013; 96(2): 214-8. [http://dx.doi.org/10.1111/cxo.12038] [PMID: 23496656]

[30] Balasubramanian SA, Wasinger VC, Pye DC, Willcox MDP. Preliminary identification of differentially expressed tear proteins in keratoconus. Mol Vis 2013; 19: 2124-34. [PMID: 24194634]

[31] Fink BA, Wagner H, Steger-May K, et al. Differences in keratoconus as a function of gender. Am J Ophthalmol 2005; 140(3): 459-68. [http://dx.doi.org/10.1016/j.ajo.2005.03.078] [PMID: 16083843]

[32] Poupliquen Y, Forman MR, Giraud JP. Evaluation of the rapidity of progression of keratoconus by a study of the relationship between age when first detected and age at operation (author s transl). Fr ophthalmol $1981 ; 4: 219-21$.

[33] Tuft SJ, Fitzke FW, Buckley RJ. Myopia following penetrating keratoplasty for keratoconus. Br J Ophthalmol 1992; 76(11): 642-5. [http://dx.doi.org/10.1136/bjo.76.11.642] [PMID: 1477036]

[34] Saini JS, Saroha V, Singh P, Sukhija JS, Jain AK. Keratoconus in Asian eyes at a tertiary eye care facility. Clin Exp Optom 2004; 87(2): 97-101. [http://dx.doi.org/10.1111/j.1444-0938.2004.tb03155.x] [PMID: 15040776]

[35] Galin MA, Berger R. Atopy and keratoconus. Am J Ophthalmol 1958; 45(6): 904-6. [http://dx.doi.org/10.1016/0002-9394(58)90403-3] [PMID: 13533502]

[36] Carlson AN. Expanding our understanding of eye rubbing and keratoconus Cornea 2010; 29(2): 245.

[37] Yildiz EH, Diehl GF, Cohen EJ, Hammersmith KM, Laibson PR, Rapuano CJ. Demographics of patients older than 50 years with keratoconus. Eye Contact Lens 2009; 35(6): 309-11. [http://dx.doi.org/10.1097/ICL.0b013e3181be5784] [PMID: 19816185]

[38] Pobelle-Frasson C, Velou S, Huslin V, Massicault B, Colin J. Keratoconus: What happens with older patients?. J Fr Ophtalmol 2004; 27(7): 779-82. [http://dx.doi.org/10.1016/S0181-5512(04)96213-4] [PMID: 15499275]

[39] Ihalainen A. Clinical and epidemiological features of keratoconus genetic and external factors in the pathogenesis of the disease. Acta Ophthalmol Suppl 1986; 178(Suppl.): 1-64. [PMID: 3019073]

[40] Romagnani S. The increased prevalence of allergy and the hygiene hypothesis: Missing immune deviation, reduced immune suppression, or both? Immunology 2004; 112(3): 352-63.

[http://dx.doi.org/10.1111/j.1365-2567.2004.01925.x] [PMID: 15196202]

[41] Pihlblad MS, Schaefer DP. Eyelid laxity, obesity, and obstructive sleep apnea in keratoconus. Cornea 2013; 32(9): 1232-6. [View at Publisher - View at Google Scholar · View at Scopus]. [http://dx.doi.org/10.1097/ICO.0b013e318281e755] [PMID: 23471083]

[42] Yeung KT, Tai JH, Weismann BA. Where have all the keratoconus patients gone? Int Contact Lens Clin 1998; 25(4): 109-13. [http://dx.doi.org/10.1016/S0892-8967(98)00028-5]

[43] Gupta PK, Stinnett SS, Carlson AN. Prevalence of sleep apnea in patients with keratoconus. Cornea 2012; 31(6): 595-9. [http://dx.doi.org/10.1097/ICO.0b013e31823f8acd] [PMID: 22333661]

[44] Beardsley TL, Foulks GN. An association of keratoconus and mitral valve prolapse. Ophthalmology 1982; 89(1): 35-7. [http://dx.doi.org/10.1016/S0161-6420(82)34857-5] [PMID: 7070771]

[45] Kristinsson JK, Carlson AN, Kim T. Keratoconus and obesity: A connection?. Investigative Ophthalmology \& Visual Science, 44, Abstract 812, 2003, ARVO E-abstract. View at Google Scholar

[46] Pihlblad MS, Schaefer DP. Eyelid laxity, obesity, and obstructive sleep apnea in keratoconus. Cornea 2013; 32(9): 1232-6. [http://dx.doi.org/10.1097/ICO.0b013e318281e755] [PMID: 23471083]

[47] Rabbanikhah Z, Javadi MA, Rostami P, et al. Association between acute corneal hydrops in patients with keratoconus and mitral valve prolapse. Cornea 2011; 30(2): 154-7.

[http://dx.doi.org/10.1097/ICO.0b013e3181e846a2] [PMID: 21045676]

[48] Moodaley LCM, Woodward EG, Liu CSC, Buckley RJ. Life expectancy in keratoconus. Br J Ophthalmol 1992; 76(10): 590-1. [http://dx.doi.org/10.1136/bjo.76.10.590] [PMID: 1420040]

[49] Spencer WH, Fisher JJ. The association of keratoconus with atopic dermatitis. Am ophthalmol 1959; 47(): 332-44.

[50] Lowell FC, Carroll JM. A study of the occurrence of atopic traits in patients with keratoconus. J Allergy 1970; 46(1): 32-9. [http://dx.doi.org/10.1016/0021-8707(70)90059-6] [PMID: 4912731]

[51] Rahi A, Davies P, Ruben M, Lobascher D, Menon J. Keratoconus and coexisting atopic disease. Br J Ophthalmol 1977; 61(12): 761-4. [http://dx.doi.org/10.1136/bjo.61.12.761] [PMID: 603783]

[52] Weed KH, MacEwen CJ, Giles T, Low J, McGhee CN. The Dundee University Scottish Keratoconus study: Demographics, corneal signs, associated diseases, and eye rubbing. Eye (Lond) 2008; 22(4): 534-41. [lond]. 
[http://dx.doi.org/10.1038/sj.eye.6702692] [PMID: 17237755]

[53] Negris R. Floppy eyelid syndrome associated with keratoconus. J Am Otpom Assoc 1992; 63: 316-9.

[54] Kuming BS, Joffe L. Ehlers-Danlos syndrome associated with keratoconus. A case report. S Afr Med J 1977; 52(10): 403-5. [PMID: 897848]

[55] McDermott ML, Holladay J, Lui D, Puklin JE, Shin DH, Cowden JW. Corneal topography in Ehler-Danlose syndrome. J Cataract Refract Surg 1998; 79: 864-733.

[56] Maumenee IH. The eye in Marfan syndrome. Trans AM Ophthol soc 1981; 79: 684-733.

[57] Beckh U, Schonherr U. Autosomal dominant keratoconus as the chief ocular syndrome in lobstein osteogenic imperfecta tarda. klin Monatsbl augenheilkd 1995; 206:268-72.

[58] Greenfield G, stein R, Romano A, Goodman RM, Blue Sclera. Keratoconus: Key features of distinct heritable disorder of connective tissue. Clin Genet 1973; 4: 8-16.

[59] Sharif KW, Casey TA, Coltart J. Prevalence of mitral valve prolapse in keratoconus patients. J R Soc Med 1992; 85(8): 446-8. [PMID: 1404188]

[60] Street DA, Vinokur ET, Waring GO III, Pollak SJ, Clements SD, Perkins JV. Lack of association between keratoconus, mitral valve prolapse, and joint hypermobility. Ophthalmology 1991; 98(2): 170-6. [http://dx.doi.org/10.1016/S0161-6420(91)32320-0] [PMID: 2008274]

[61] Cullen JF, Butler HG. Mongolism and keratoconus. Br J Ophthalmol 1963; 47: 321-30. [http://dx.doi.org/10.1136/bjo.47.6.321] [PMID: 14189698]

[62] Liza-Sharmini AT, Azlan ZN, Zilfalil BA. Ocular findings in Malaysian children with Down syndrome. Singapore Med J 2006; 47(1): 14-9. [PMID: 16397715]

[63] Shapiro MB, France TD. The ocular features of Down's syndrome. Am J Ophthalmol 1985; 99(6): 659-63. [http://dx.doi.org/10.1016/S0002-9394(14)76031-3] [PMID: 3160242]

[64] Kuo IC, Broman A, Pirouzmanesh A, Melia M. Is there an association between diabetes and keratoconus? Ophthalmology 2006; 113(2): $184-90$. [http://dx.doi.org/10.1016/j.ophtha.2005.10.009] [PMID: 16368147]

[65] Elder MJ. Leber congenital amaurosis and its association with keratoconus and keratoglobus. J Pediatr Ophthalmol Strabismus 1994; 31(1): $38-40$. [PMID: 8195961]

[66] Darlington JK, Mannis MJ, Segal WA. Anterior keratoconus associated with unilateral cornea guttata. Cornea 2001; 20(8): 881-4. [http://dx.doi.org/10.1097/00003226-200111000-00021] [PMID: 11685071]

[67] Javadi MA. Rafee's. concomitant keratoconus associated with corneal granular dystrophy. Cornea 2004; 23: 508-12. [http://dx.doi.org/10.1097/01.ico.0000114124.63670.dd] [PMID: 15220737]

[68] Shneor E, Millodot M, Gordon Shaag A, et al. Prevelance of keratoconus among young Arab students in Israel, Inter. Kerat Ect Cor Dis 2014; 3(1): 9-14.

[69] Assiri AA, Yousuf BI, Quantock AJ, Murphy PJ. Incidence and severity of keratoconus in Asir province, Saudi Arabia. Br J Ophthalmol 2005; 89(11): 1403-6.

[http://dx.doi.org/10.1136/bjo.2005.074955] [PMID: 16234439]

\section{(C) 2018 Khor Omer.}

This is an open access article distributed under the terms of the Creative Commons Attribution 4.0 International Public License (CC-BY 4.0), a copy of which is available at: (https://creativecommons.org/licenses/by/4.0/legalcode). This license permits unrestricted use, distribution, and reproduction in any medium, provided the original author and source are credited. 